\title{
Considering mesohabitat scale in ecological impact assessment of sediment flushing
}

\author{
Alberto Doretto $^{1,2}$ [D, Paolo Espa ${ }^{3}$ (1), Francesca Salmaso ${ }^{4}$, Giuseppe Crosa $^{4}$ (1) and Silvia Quadroni ${ }^{4}{ }^{*}$ (1) \\ ${ }^{1}$ Department of Sciences and Technological Innovation, University of Piemonte Orientale, Viale Teresa Michel 11, 15121 Alessandria, \\ Italy \\ 2 ALPSTREAM - Alpine Stream Research Center, 12030 Ostana, Italy \\ ${ }^{3}$ Department of Science and High Technology, University of Insubria, Via GB Vico 46, 21100 Varese, Italy \\ ${ }^{4}$ Department of Theoretical and Applied Sciences, University of Insubria, Via JH Dunant 3, 21100 Varese, Italy
}

Received: 16 August 2021 / Accepted: 11 December 2021

\begin{abstract}
Benthic macroinvertebrates respond to several factors characterizing the physical habitats, as water depth, current and streambed substrate. Thus, anthropogenic disturbances altering these factors may have different effects on benthos, also depending on mesohabitats. These disturbances include sediment flushing operations, commonly carried out to recover reservoir capacity, and investigating their effects at mesohabitat scale could be relevant for an adequate ecological impact assessment of these operations. Here, we compared benthic macroinvertebrate communities sampled before and after a controlled sediment flushing operation in three different mesohabitats (a pool, a riffle and a step-pool) of an Alpine stream. Contrary from expectations, the composition of macroinvertebrate assemblages was not significantly different among mesohabitats. Moreover, the impact of sediment flushing was more significant in terms of density rather than in richness. Two stressor-specific indices were tested, but only one (the Siltation Index for LoTic EcoSystems - SILTES) clearly detected the impact of sediment flushing on the macroinvertebrate community structure. Finally, some differences in the temporal trajectories and recovery times to preflushing conditions were observed among mesohabitats, both if the three mesohabitats were considered separately and if all their possible combinations were accounted for. Particularly, riffle was the most sensitive mesohabitat, not fully recovering one year after the sediment disturbance.
\end{abstract}

Keywords: Pool / riffle / step-pool / macroinvertebrates / stressor-specific index

\section{Introduction}

Stream habitats are characterized by multiple physical factors, including water depth, current and substrate size, controlling the abundance, distribution and productivity of stream-dwelling organisms. Particularly, stream biota responds and adapts to the patterns of physical habitats within channel units (hereafter called mesohabitats), i.e., relatively homogeneous localized areas of the channel that differ in morphology, depth, velocity, and substrate characteristics from adjoining areas, such as pools and riffles (Bisson et al., 2017). Stream-dwelling organisms have different sensitivity to the mentioned factors. For instance, bottom-dwelling animals as benthic macroinvertebrates are mainly controlled by shear stress (Gibbins et al., 2007, 2010) and substrate (Beisel et al., 1998; Barnes et al., 2013). The taxonomic structure of

\footnotetext{
${ }^{*}$ Corresponding author: silvia.quadroni@uninsubria.it
}

macroinvertebrates is known to differ between riffles and pools, especially in headwater streams (Herbst et al., 2018). The highest species richness is usually detected in riffles, where a mix of coarser particles provides the most favorable habitat for reophilous taxa, while substrates rich in silt and organic matter can support large populations of burrowing animals as the Diptera Chironomidae (Gordon et al., 2004; Barnes et al., 2013). According to Silva et al. (2014), mesohabitats are crucial in ecological and biodiversity assessments through macroinvertebrate sampling: being a proxy for several hydraulic and morphological community drivers, they explain significant amounts of beta-diversity, thus they are important predictors of assemblage composition.

Streambed substrate is subjected to changes, predominantly to fine sediment deposition, following sediment disturbance events such as sediment flushing operations from reservoirs (Espa et al., 2019). These changes may significantly differ between mesohabitats due to different hydraulic and consequently depositional conditions. For instance, a higher Froude 
number (i.e., a proxy of hydraulic conditions) was associated with a lower level of sediment accumulation in a riffle area than in a glide area of an Alpine river after an extreme sediment input (Salmaso et al., 2021). Therefore a specific focus on the mesohabitat scale may be an important step towards a thorough assessment of the ecological impact of sediment flushing, especially in patchy stream environments. Sediment disturbance associated with reservoir flushing is becoming more frequent in the last decades, due to the need of recovering the storage capacity of reservoirs mostly built in the last century. Several examples are documented in the European Alps, Japan and China (Kondolf et al., 2014; Espa et al., 2019). Although some mitigation measures have been already implemented for reducing the impact on the freshwater environment (Espa et al., 2015, 2016; Quadroni et al., 2016; Doretto et al., 2019; Folegot et al., 2021), the ecological effects of flushing operations are not yet completely understood, thus preventing adequate action by environmental protection authorities and water resource managers (Owens et al., 2005). For instance, in Italy, the assessment of the ecological impact of flushing operations is usually carried out by applying the standard protocols developed within the European Union Water Framework Directive (WFD) to defining the ecological status of water bodies (e.g., Espa et al., 2015, 2016; Doretto et al., 2019). Specifically, among the four riverine biological quality elements (i.e., diatoms, macrophytes, benthic macroinvertebrates and fish) accounted for by the WFD, benthic macroinvertebrates are the most considered in this context. Moreover, sampling is commonly limited to one mesohabitat, mostly riffle, and the adopted normative index (Standardization of River Classifications_Intercalibration Common Metric index - STAR_ICMi, Buffagni and Erba, 2007) revealed some limits in detecting the impact of specific pressures such as sediment flushing (Espa et al., 2015, 2016; Doretto et al., 2019, 2021).

In this work, we investigated the relevance of mesohabitats in ecological impact assessment of sediment flushing adopting benthic macroinvertebrates as bioindicators, and accounting for indices specific to detect sediment pressures. For this purpose, we used as a case study the sediment flushing operation carried out on September 2018 from a small Alpine reservoir in northern Italy. The operation affected a small upland stream (the Roasco Stream) characterized by marked physical heterogeneity, and providing different types of mesohabitats, each other in close proximity. Specifically, within a $1 \mathrm{~km}$-long stretch, a pool, a riffle and a step-pool were selected and sampled. According to different available habitats (Halwas et al., 2005), we expected a different abundance and distribution of benthic macroinvertebrates before the sediment flushing event, and different changes induced by this anthropogenic disturbance among the three mesohabitats (Silva et al., 2014; Salmaso et al., 2021). In order to evaluate the role played by mesohabitats, the response of macroinvertebrates to sediment flushing was evaluated both for single mesohabitats, and for groups of mesohabitats (i.e., pairs and the three mesohabitats together). In fact, it is important to take into account also the contribution of different mesohabitats to the community composition of the investigated reach before sediment flushing, and then to assess possible differences of the community response to the flushing operations caused by different mesohabitat changes. Moreover, we tested the only two indices specific to detect siltation impact developed for the Alpine context, i.e., the Siltation Index for LoTic EcoSystems (SILTES - Doretto et al., 2018a, 2021) and the Deposited Fine Sediment Index (DFSI Gieswein et al., 2019). We expected that both these indices were suitable to detect the impact of an anthropic activity causing a relevant sediment pressure such as sediment flushing, and thus that they could be routinely applied for the biomonitoring of these operations. We focused our analysis on benthic macroinvertebrates both because of their great features and their wide use as bioindicators (Buss et al., 2015), and because of their importance within the stream community as a fundamental link in the food web between organic matter resources and fishes (Rosenberg and Resh, 1993; De Pauw et al., 2006).

\section{Materials and methods}

\subsection{Study area and context}

The Valgrosina Reservoir ( $1.3 \mathrm{Mm}^{3}$ storage capacity) is located in the Rhaetian Alps (northern Italy), at $1210 \mathrm{~m}$ amsl (top of the active pool). The reservoir is fed directly by the Roasco d' Eita Stream and, through a short canal, by the Roasco di Sacco Stream. These two streams join a kilometer downstream of the reservoir and then the Roasco Stream flows for $7.8 \mathrm{~km}$ up to the Adda River, i.e., the main tributary of Lake Como (Fig. 1).

The Roasco is a high gradient (0.08 average slope), confined stream with large, stable boulders, and abrupt drops. It flows mainly through a deeply incised canyon in predominantly gneissic rocks. Access is rather difficult, except for the final $2 \mathrm{~km}$ where the profile is smoother and the slope ranges from 0.025 to 0.045 . Our field investigation thus focused on this final reach of the stream (Fig. 1). Natural drainage area at the study reach is $145 \mathrm{~km}^{2}$. The catchment mainly develops in a mountainous area $(3200 \mathrm{~m}$ amsl max elevation) lacking significant human activities; nutrient and organic pollution is indeed negligible for the Roasco Stream (Quadroni et al., 2017). Natural runoff is mainly driven by snowmelt in spring and early summer, and by rainfall, occasionally intense, in summer and autumn; the mean annual natural discharge at the study section is $4.5 \mathrm{~m}^{3} / \mathrm{s}$. Impounding the Roasco Stream began in 1925 by a small dam about half a kilometer below the current Valgrosina Dam, which was closed in 1960 . Since 2009 , mandatory minimum flows of 0.24 $\mathrm{m}^{3} / \mathrm{s}$ from November to April and $0.41 \mathrm{~m}^{3} / \mathrm{s}$ from May to October have been released in the Roasco Stream from the Roasco di Sacco intake. However, an average streamflow of approximately $1 \mathrm{~m}^{3} / \mathrm{s}$ was detected at the study reach from 2010 to 2014 , also due to the contribution by the $15 \mathrm{~km}^{2}$ unexploited catchment (Quadroni et al., 2017).

Since 2006, controlled sediment flushing operations of the Valgrosina Reservoir have been carried out almost annually, following a consolidated protocol (Crosa et al., 2010; Espa et al., 2013). They take place at the same season (between August and September) over approximately two weeks. According to the sediment flushing schedule, suspended sediment concentrations increased during daytime (approximately up to $10 \mathrm{~g} / \mathrm{L}$ ), and decreased overnight (approximately $1 \mathrm{~g} / \mathrm{L}$ ), when the dislodging works by mechanical equipment are interrupted. Moreover, at the study reach, the concentration 

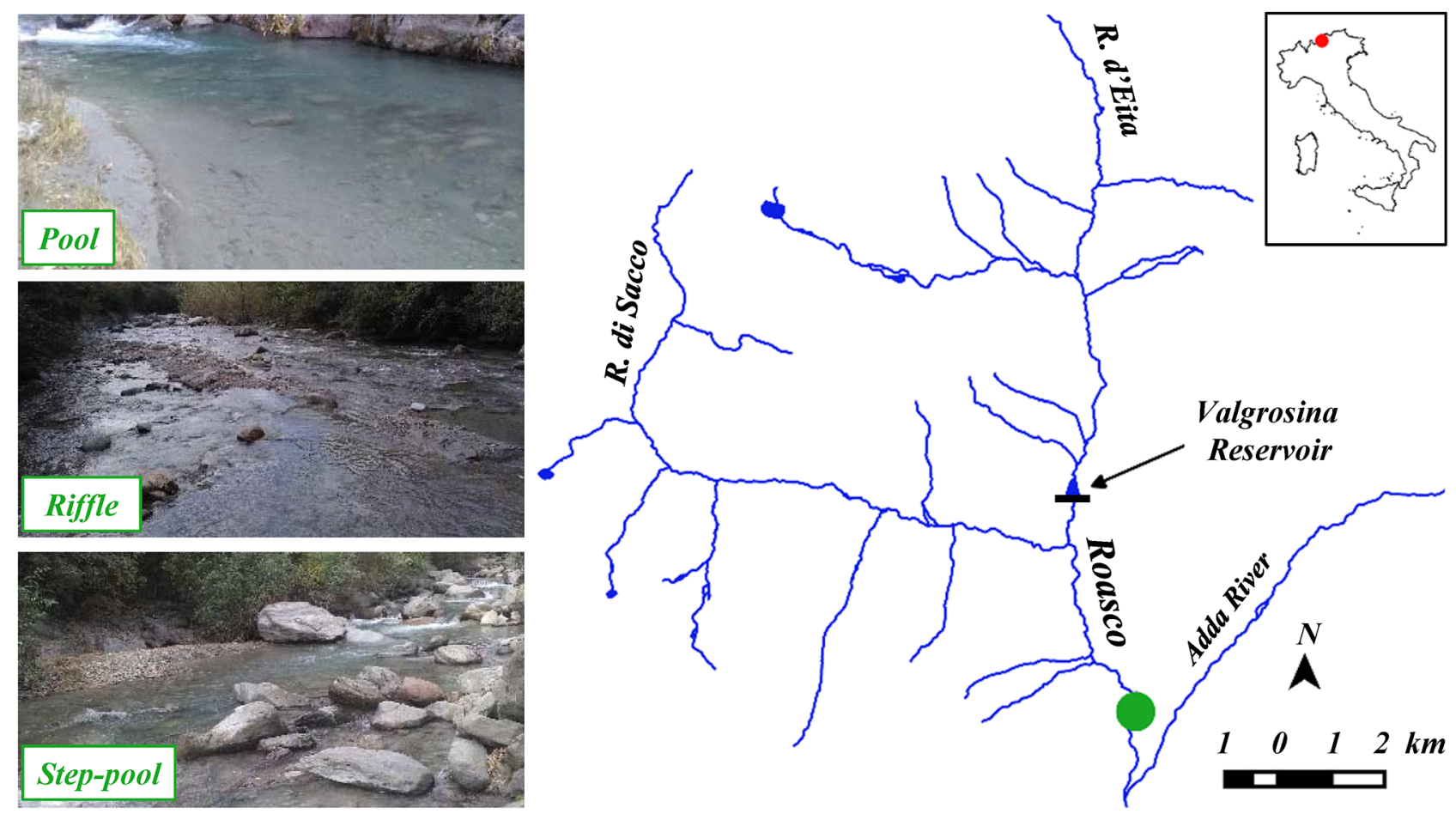

Fig. 1. Study area and sampling sites. Position of the study reach of the Roasco Stream downstream of the Valgrosina Reservoir in northern Italy, and photos of the three mesohabitats sampled, approximately $250 \mathrm{~m}$ spaced each other.

Table 1. Main characteristics of the three mesohabitats investigated in this study. Microhabitat composition: sand $=<0.2 \mathrm{~cm}$, gravel $=0.2-2 \mathrm{~cm}$, microlithal $=2-6 \mathrm{~cm}$, mesolithal $=6-20 \mathrm{~cm}$, macrolithal $=20-40 \mathrm{~cm}$, megalithal $=>40 \mathrm{~cm}$ (Buffagni and Erba, 2007); the average depth was measured at a flow rate of $1.2 \mathrm{~m}^{3} / \mathrm{s}$ by sampling at least 15 points.

\begin{tabular}{llll}
\hline Characteristics & Pool & Riffle & Step-pool \\
\hline Length (m) & 17 & 18 & 13 \\
Upstream width (m) & 9.5 & 13 & 7 \\
Downstream width (m) & 9.5 & 18 & 8 \\
Average depth (cm) & 46 & 21 & 31 \\
Elevation (m aslm) & 677 & 670 & 647 \\
Microhabitat composition & $40 \%$ sand-gravel & $40 \%$ microlithal & $40 \%$ gravel $/$ microlithal \\
& $20 \%$ gravel & $40 \%$ mesolithal & $40 \%$ macrolithal \\
& $20 \%$ microlithal & $20 \%$ macrolithal & $20 \%$ megalithal \\
\hline
\end{tabular}

over the whole operation should not exceed the maximum permitted value of $4 \mathrm{~g} / \mathrm{L}$. During the activities, the average water discharge was larger than the minimum flow, usually approaching the mean annual natural flow. Evacuated sediment, predominantly silt, amounted to around 20,000 tons per operation. Most of the sediment was usually transported in suspension, giving limited sediment deposition in the riverbed areas wetted at base flow (estimated to $1-2.5 \mathrm{~kg} / \mathrm{m}^{2}$ in the study reach - Espa et al., 2013).

We investigated the effects of the controlled sediment flushing operation performed from September 10 to 21, 2018 by selecting three sampling sites characterized by a different mesohabitat: a pool, a riffle and a step-pool spaced each other by $250 \mathrm{~m}$ (Fig. 1, Tab. 1).

\subsection{Benthic macroinvertebrates sampling and analysis}

Sampling of benthic macroinvertebrates was performed five days before (September 5, 2018-Before) and five times in the year after the sediment flushing, in accordance with the national (DM 30/6/2004) and regional (DGR n.5736/2016) normative. Specifically, few weeks after the operation (October 8, 2018-Post01), and with time interval of 
two-three months (December 3, 2018, March 21, July 9, September 12, 2019, Post02 to Post05 respectively). Benthic macroinvertebrates were sampled with a Surber sampler $\left(0.1 \mathrm{~m}^{2}\right.$ area and $500 \mu \mathrm{m}$ mesh; Doretto et al., 2020). Five subsamples were collected in representative microhabitats according to related abundance (Tab. 1), and then integrated in a single sample per mesohabitat. Samples were fixed with ethanol $(99 \%)$ and transported to the laboratory, where invertebrates were sorted, identified to genus (Plecoptera and Ephemeroptera) or family level, and counted. Density (individuals $/ \mathrm{m}^{2}$ ) was determined for each taxon.

\subsection{Data analysis}

In this study, seven mesohabitat "scenarios" were evaluated by considering both the single mesohabitats (i.e., pool, riffle and step-pool) and all their possible combinations: $\mathrm{PR}=$ pool and riffle, $\mathrm{PSP}=$ pool and step-pool, $\mathrm{RSP}=$ riffle and step-pool, PRSP = pool, riffle and step-pool. This allowed us to test if the impacts of the flushing operations and the subsequent recovery of macroinvertebrate community were affected by the choice of the mesohabitat to be sampled, including single mesohabitat and their possible combinations. Starting from the macroinvertebrate data collected separately from the riffle, pool and step-pool, for each combination of mesohabitats the corresponding community was obtained by pooling together the data of single mesohabitats. For example, the macroinvertebrate community of PR (i.e., pool and riffle) was obtained by pooling together the taxa collected in the pool with those collected in the riffle. To this end, taxon density attributed to mesohabitat combinations was the average of corresponding densities measured in single mesohabitats.

Differences in the community composition between mesohabitat scenarios and sampling occasions were visually and statistically examined by non-metric multidimensional scaling (nMDS) and permutational multivariate analysis of variance (PERMANOVA), respectively. Whether a factor (i.e., mesohabitats or sampling occasions) was significant, then the pairwise comparisons were performed to test for statistical significance. The Bray-Curtis dissimilarity was applied to macroinvertebrate abundances after square-root transformation.

For each mesohabitat and their combinations the following community metrics and biomonitoring indices were calculated: total taxon richness, total density (individuals $/ \mathrm{m}^{2}$ ), EPT (Ephemeroptera, Plecoptera and Trichoptera) richness, density of macroinvertebrates belonging to Ecological Group A, that is rheophilous taxa preferring coarse substrates, typical of oligotrophic, alpine habitats (sensu Usseglio-Polatera et al., 2000), and SILTES and DFSI indices.

The SILTES index accounts for total taxon richness, EPT richness and Ecological Group A density. It was calculated as the average of the values of the three metrics scaled accounting for the whole dataset, i.e., by subtracting the value of the metric of the considered sample for the minimum value of this metric observed in the dataset and dividing the obtained value by the range min-max of the metric. The index value ranges from 0 (worst condition) to 1 (best condition) (for details see Doretto et al., 2018a, 2021).
The DFSI index was developed by using indicator taxa identified through the application of the threshold indicator taxa analysis (TITAN). The sum of each individual taxon's median multiplied by the corresponding z-score and the abundance class, was divided by the sum of $\mathrm{z}$-score multiplied by the abundance class. Higher index values indicate higher fine sediment impact (for details see Gieswein et al., 2019).

Chi-square test was applied to evaluate significant differences for each of the community metrics and biomonitoring indices (except for SILTES) between sampling occasions for each mesohabitat and their combinations (significance threshold: $p=0.05$ ).

All statistical analysis were run with the $\mathrm{R}$ software ( $\mathrm{R}$ Core Team, 2019), using the basic functions and vegan $\mathrm{R}$ package (Oksanen et al., 2015) for nMDS and PERMANOVA.

\section{Results}

A total of 28 taxa was detected in the study reach, 24 in the riffle and in the pool and 26 in the step-pool. The average density over the whole study period was $301( \pm 249), 550$ $( \pm 450)$ and $670( \pm 428)$ individuals $/ \mathrm{m}^{2}$ in the step-pool, pool and riffle respectively. Most families of benthic macroinvertebrates were common to the three mesohabitats and belong to five insect orders (Tab. 2). In particular, the dominant family in the Before samples was the Ephemeroptera Baetidae, represented only by the genus Baetis, followed by the Diptera Chironomidae. Some families such as the Trichoptera Limnephilidae, and the Diptera Limoniidae and Empididae displayed the highest densities in the pool, while other families such as the Trichoptera Hydropsychidae and Rhyacophilidae, and the Coleoptera Elmidae in the riffle. In the pool, most families displayed the highest densities in Post05, while in the riffle and step-pool in the Before or Post03 samples.

PERMANOVA and nMDS ordination (stress $=0.13$; Fig. 2) depicted a significant variation in the taxonomic composition of macroinvertebrate communities between sampling occasions $\left(F_{5,36}=17.7 ; p<0.001\right)$, but not between mesohabitats and their combinations $\left(F_{6,35}=0.59 ; p=0.974\right)$. Post01 samples were all oriented on the bottom-right panel of the ordination plot, while Post 02 and Post 03 on the bottom-left panel. Post04 samples were also separated from the other sampling occasions and placed on the top-right panel of the graph, whereas the Before samples and Post05, which are those collected one year after sediment flushing, were on the top-left panel of the nMDS ordination plot (Fig. 2). Pairwise comparisons between sampling occasions were always significant, with the exception of that between Before and Post05 samples (Tab. 3).

No significant variations in taxon richness were observed over time for single mesohabitat or their combinations. The total number of taxa decreased after sediment flushing in the three mesohabitats (Fig. 3a-c), then it fluctuated over time in the pool and step-pool, with peaks especially on Post03 and Post05. By contrast, taxon richness further decreased in the riffle until Post04 and partially recovered only on the last sampling occasion. When looking at combinations of mesohabitats, similar trends were observed: compared to the Before samples, the total number of taxa decreased on Post01 
A. Doretto et al:: Knowl. Manag. Aquat. Ecosyst. 2022, 423, 2

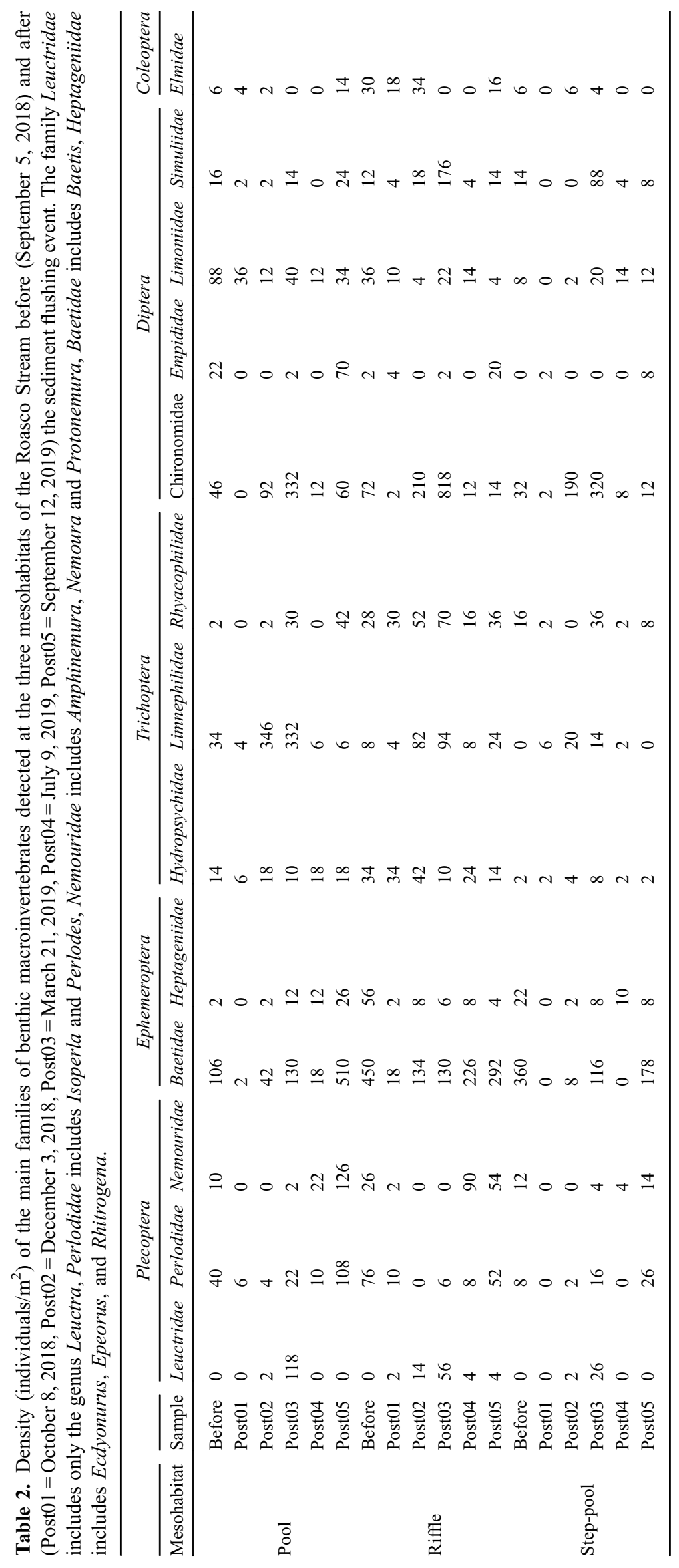




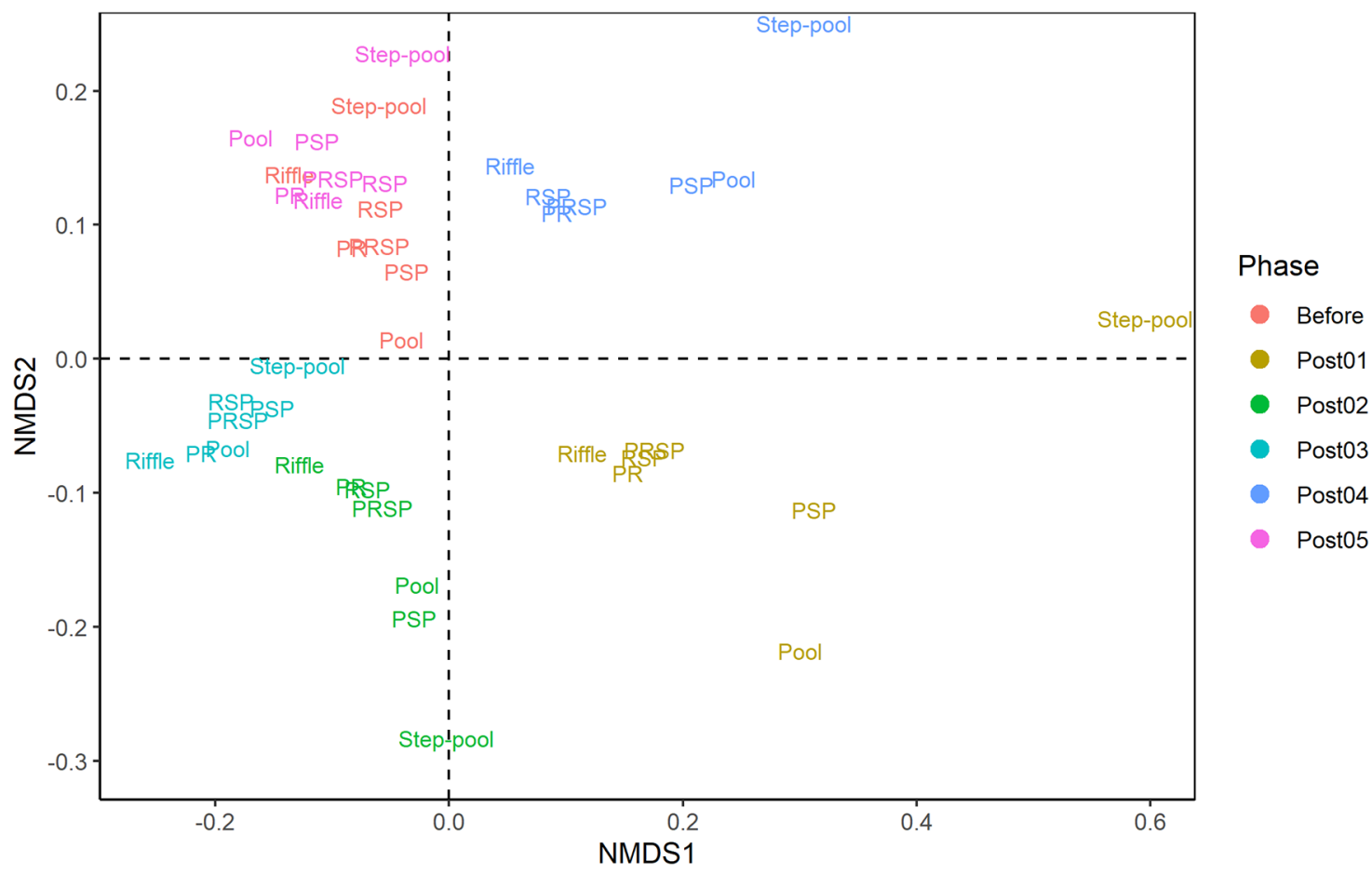

Fig. 2. nMDS ordination plot of the macroinvertebrate communities in relation to sampling occasions and mesohabitats. Different colors indicate the sampling phases (Before, Post01 to Post05), while labels indicate mesohabitats (Pool, Riffle, Step-pool, PR=Pool and Riffle, $\mathrm{PSP}=$ Pool and Step-pool, RSP $=$ Riffle and Step-pool, PRSP $=$ Pool, Riffle and Step-pool).

Table 3. Pairwise comparisons of PERMANOVA between sampling occasions: $F=$ pseudo $F$-value, $p=p$-value.

\begin{tabular}{lll}
\hline Pairwise comparison & $F_{1,12}$ & $p$ \\
\hline Before-Post01 & 17.4 & 0.030 \\
Before-Post02 & 21.4 & 0.015 \\
Before-Post03 & 29.9 & 0.045 \\
Before-Post04 & 12.0 & 0.030 \\
Before-Post05 & 3.1 & 0.375 \\
Post01-Post02 & 16.9 & 0.045 \\
Post01-Post03 & 25.1 & 0.045 \\
Post01-Post04 & 7.5 & 0.015 \\
Post01-Post05 & 20.2 & 0.015 \\
Post02-Post03 & 13.2 & 0.015 \\
Post02-Post04 & 16.4 & 0.030 \\
Post02-Post05 & 28.5 & 0.030 \\
Post03-Post04 & 22.8 & 0.030 \\
Post03-Post05 & 36.3 & 0.030 \\
Post04-Post05 & 13.9 & 0.015 \\
\hline
\end{tabular}

and then fluctuated over time with peaks on Post03 and Post05, after six months and one year from sediment flushing respectively (Fig. 3d-g).

Unlike taxon richness, temporal variation in the total density of macroinvertebrates was always significant. Riffle was the mesohabitat with the highest density on the Before sampling occasion (890 individuals $/ \mathrm{m}^{2}$ ), which abruptly dropped to 156 individuals $/ \mathrm{m}^{2}$ after sediment flushing. Then, the density increased over time with a peak on Post03 (Fig. 3i). Pool and step-pool had a lower density before sediment flushing, and very similar recovery patterns were also found for these mesohabitats (Fig. 3h and j), even though an additional peak on the last sampling occasion was detected in the pool. When looking at combinations of mesohabitats, very consistent and comparable trends were found (Fig. 3k-n). Total density collapsed after sediment flushing and then fluctuated over time with peaks on Post03 and Post05 and an additional decrease on Post04.

No significant variations in EPT richness over time were observed for single mesohabitats and their combinations. Compared to the Before samples, the number of EPT taxa decreased after sediment flushing in the pool (Fig. 4a), riffle (Fig. 4b) and step-pool (Fig. 4c), but then no clear trends were observed on the other sampling occasions with exception of the step-pool, where a peak was detected on Post03. Among mesohabitat combinations, PR (i.e., pool and riffle; Fig. 4d) showed the lowest variation in EPT richness over time, while the other combinations (Fig. 4e-g) had very similar temporal patterns, characterized by a moderate to negligible drop in EPT richness on Post01 and a peak on Post03, reflecting the trend observed for the step-pool.

Temporal variation in the density of macroinvertebrates belonging to Ecological Group A was always significant for each mesohabitat and their combinations. The most remarkable changes were observed in the pool (Fig. 4h), where the density of these taxa varied from 46 individuals $/ \mathrm{m}^{2}$ before sediment flushing to 4 individuals $/ \mathrm{m}^{2}$ after sediment flushing (i.e., Post01). Then, considerable peaks were recorded on 

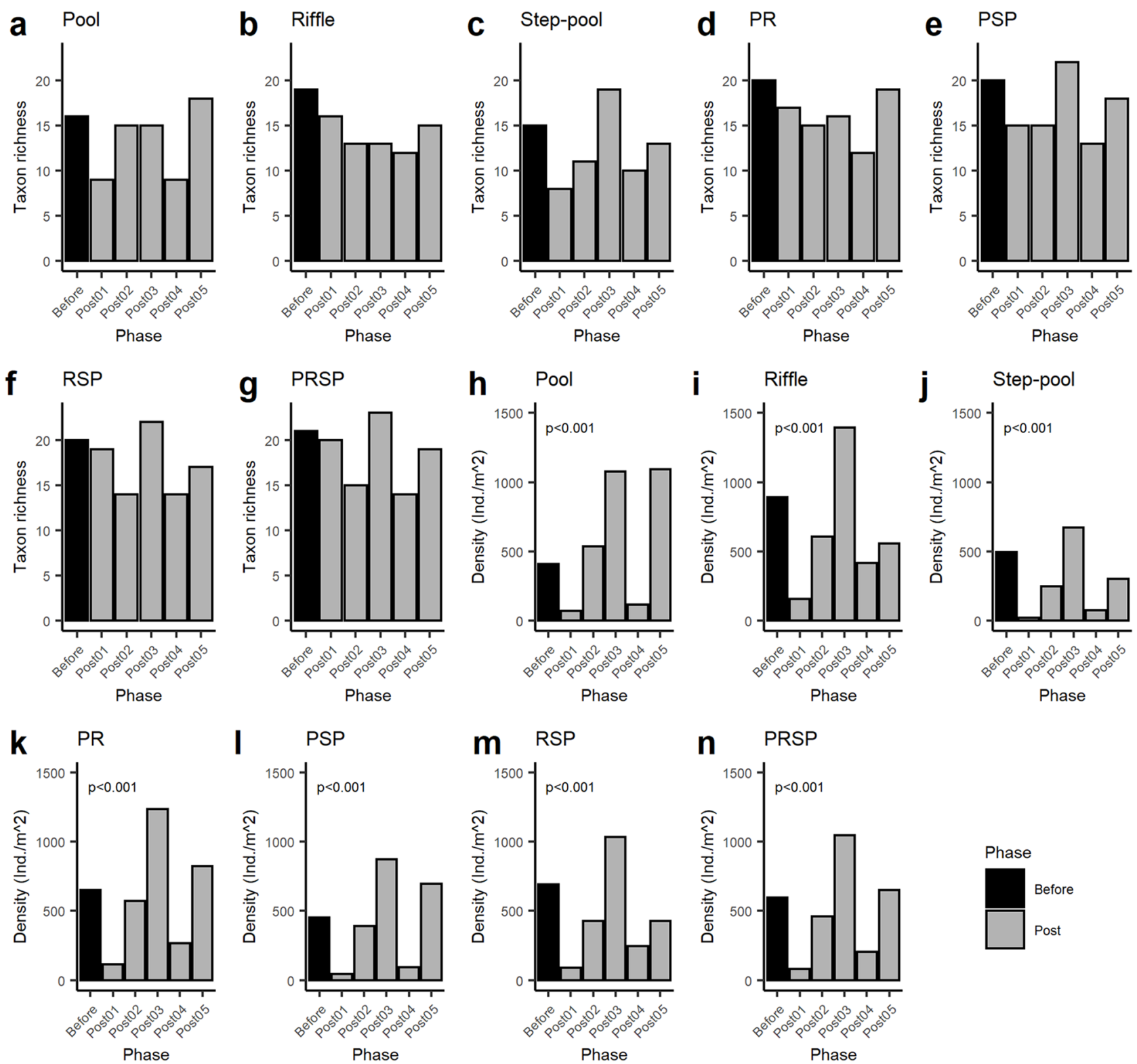

Fig. 3. Bars represent the total taxon richness $(\mathrm{a}-\mathrm{g})$ and total density of macroinvertebrates $(\mathrm{h}-\mathrm{n})$ on each sampling occasion for each mesohabitat (Pool, Riffle, Step-pool, PR = Pool and Riffle, PSP = Pool and Step-pool, RSP = Riffle and Step-pool, PRSP = Pool, Riffle and Steppool).

Post02 and Post03 (explained by the high densities of Limnephilidae, Tab. 2) followed by a decrease on Post04 and an additional peak one year after sediment flushing (i.e., Post05). By contrast, riffle and step-pool (Fig. 4i-j) showed very similar temporal patterns, despite the Ecological Group A density was higher in the former than in the latter mesohabitat. After a marked decrease on Post01, the density of these macroinvertebrates recovered since Post02 and/or Post03, with negligible variations on the last sampling occasions. The variations observed for the pool strongly affected the patterns of mesohabitat combinations including it, so that PR, PSP and PRPS showed temporal patterns very similar to that of the pool considered individually (Fig. 4k, 1, n). In contrast, RSP (Fig. $4 \mathrm{~m}$ ) closely resembled the temporal variation observed for the riffle and step-pool.
Differences in the temporal variation of the two selected biomonitoring indices were noticed (Fig. 5). Although a clear reduction in the SILTES index was found in the pool, riffle and step-pool after sediment flushing, its scores and temporal trends varied remarkably between mesohabitats. In the pool, the SILTES index varied from 0.63 before sediment flushing to 0 on Post01. Then, it recovered fast over time, reaching higher values than Before sample, with exception of Post04, when it dropped to 0.17 (Fig. 5a). In the riffle the SILTES index was 0.87 before sediment flushing and after this disturbance it decreased and never recovered, despite increases were observed on Post03 and Post05 (Fig. 5b). In the step-pool the SILTES index was 0.62 before sediment flushing and collapsed to 0 on Post 01 . Then, it progressively increased over time with a peak on Post03, when it reached the maximum 

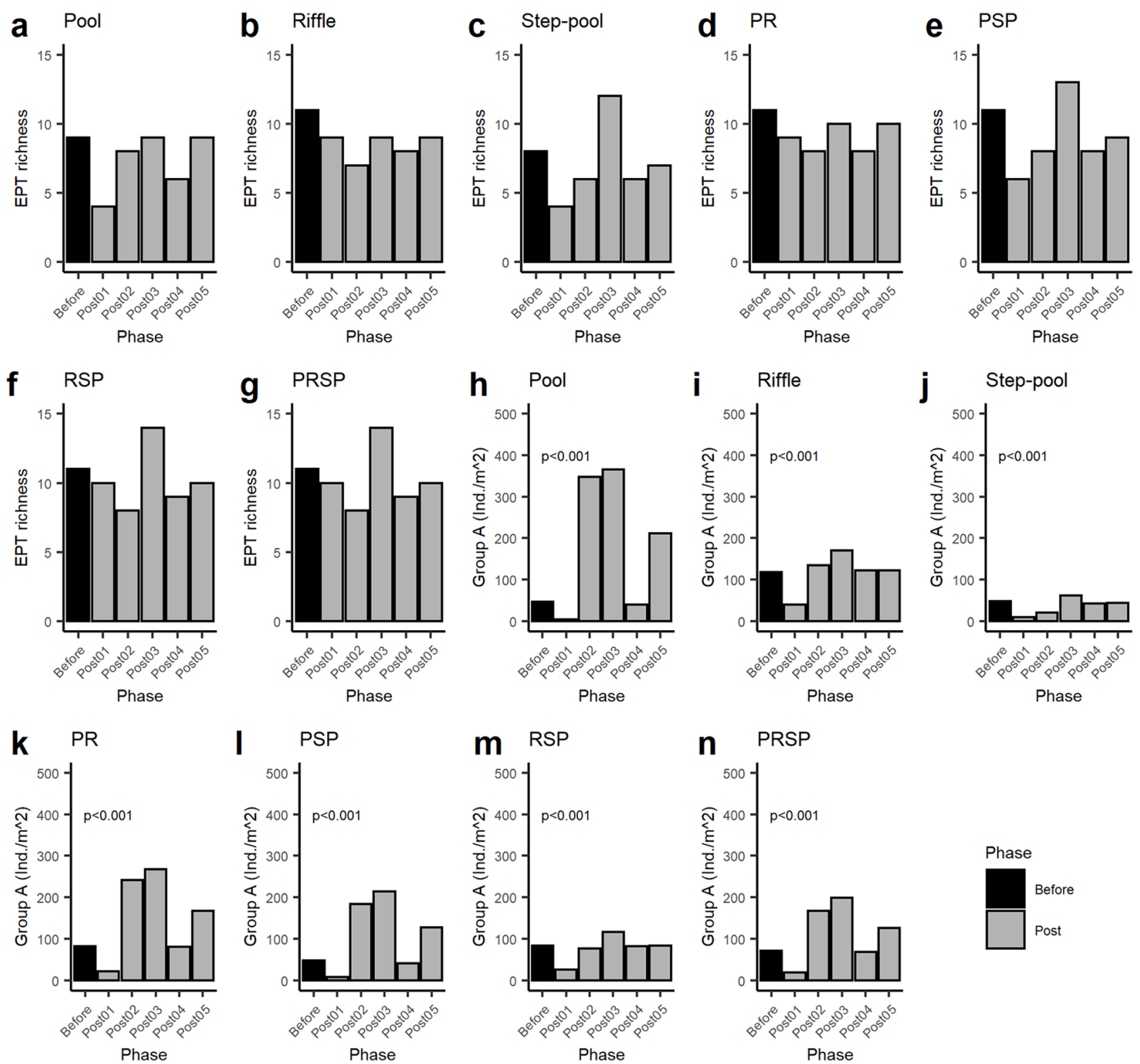

Fig. 4. Bars represent the EPT richness $(\mathrm{a}-\mathrm{g})$ and density of macroinvertebrates belonging to Ecological Group A ( $\mathrm{h}-\mathrm{n})$ on each sampling occasion for each mesohabitat (Pool, Riffle, Step-pool, PR = Pool and Riffle, PSP = Pool and Step-pool, RSP $=$ Riffle and Step-pool, PRSP $=$ Pool, Riffle and Step-pool)

value (i.e., 1; Fig. 5c). These patterns strongly affected those of mesohabitat combinations. When combining pool and riffle (i.e., PR; Fig. 5d), the SILTES index halved from 0.75 before sediment flushing to 0.32 on Post 01 . Then, this index increased over time with a full recovery on Post03 and after one year from sediment flushing (i.e., Post05), despite a marked reduction on Post04. PSP, RSP and PRSP showed similar temporal variations: after a clear reduction on Post01, the SILTES index fluctuated over time with a considerable peak on Post03 (Fig. 5e, f, g). Recovery to before-flushing conditions after one year was evident for PSP and PRSP, but to a minor extent for RSP $($ Before $=0.63$, Post05 $=0.45$ ).

Unlike the SILTES index, moderate to negligible temporal variations in the DFSI index were observed for each mesohabitat and their combinations (Fig. 5h-n). Significant changes were found only for the pool (Fig. 5h) and step-pool (Fig. 5j): in the former, an increase from 1378 before sediment flushing to 1507 on Post01 was observed, while in the latter this index decreased from 1374 to 1247 .

\section{Discussion}

Research on sediment impacts is mostly performed on riffles (Buendia et al., 2011; Mathers and Wood, 2016), and this also occurs for sediment flushing operations in regulated rivers (Espa et al., 2019). Assessing the biological response of a single mesohabitat could give an incomplete picture of the ecological impact of anthropogenic activities on the complex river ecosystem (Silva et al., 2014; Aksamit et al., 2021). 

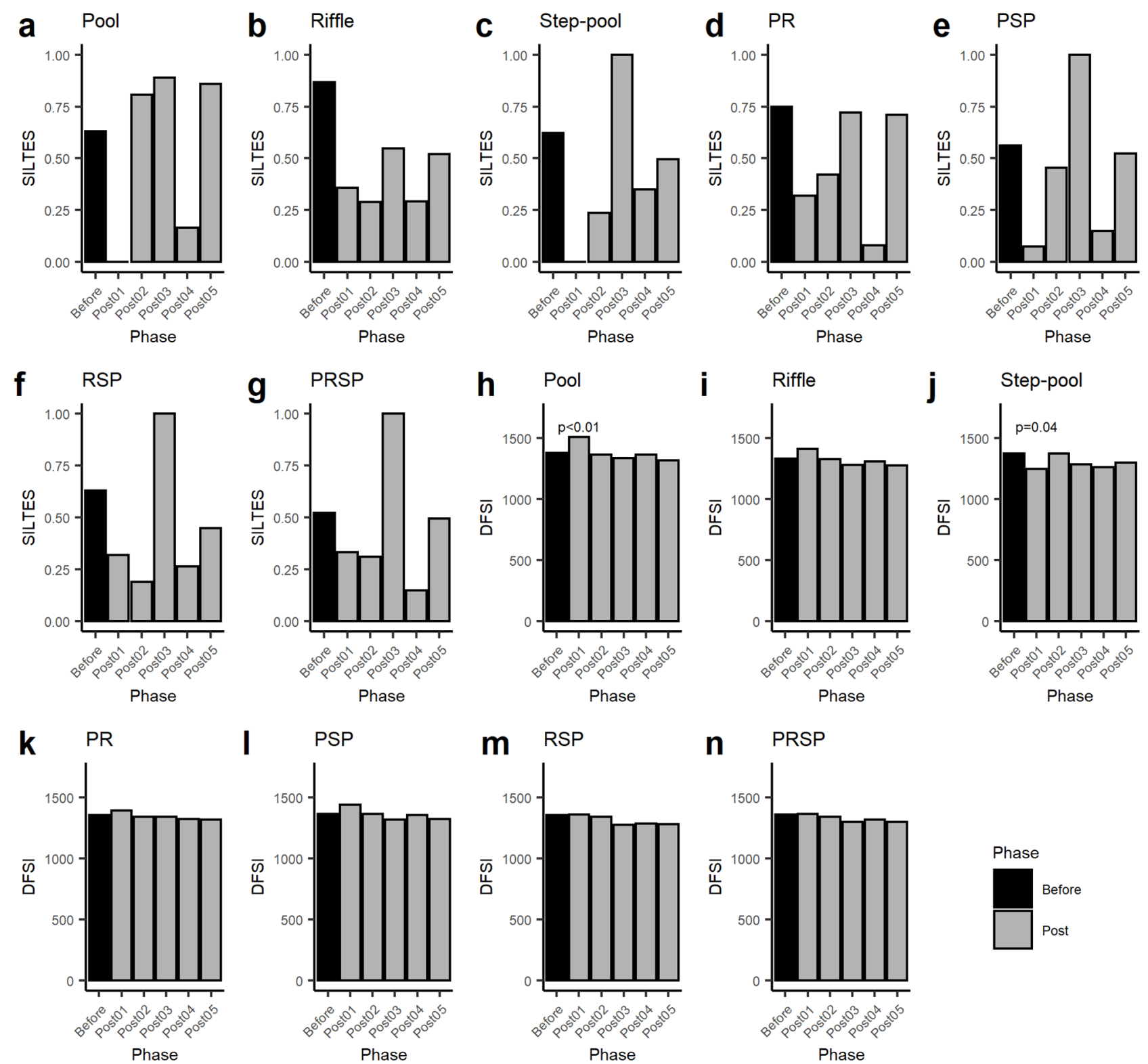

Fig. 5. Bars represent the SILTES (a-g) and DFSI (h-n) indices on each sampling occasion for each mesohabitat (Pool, Riffle, Step-pool, $\mathrm{PR}=$ Pool and Riffle, PSP $=$ Pool and Step-pool, RSP $=$ Riffle and Step-pool, PRSP $=$ Pool, Riffle and Step-pool)

Conversely, adopting a mosaic approach can increase scientific understanding of organismal-habitat relationships, supporting effective conservation of biodiversity in human-altered ecosystems (Hitchman et al., 2018). Moreover, this meets the needs for replicable and standardized data collection, a pre-requisite of many modern biomonitoring protocols based on the multi-habitat sampling scheme (Barbour et al., 1999; Friberg et al., 2005). To our knowledge, this is the first study with the objective to measure and compare the response and recovery of benthic macroinvertebrates to sediment flushing in three different mesohabitats. Our investigation tested how the benthic macroinvertebrate communities of an Alpine stream changed in richness, density, and composition after a sediment flushing event, comparing a pool, a riffle and a step-pool, and also accounting for their possible combinations. The presence of these mesohabitats in the same river reach allowed us to provide seven different mesohabitat scenarios to evaluate how biomonitoring results, i.e., the community response, can change according to the mesohabitat/s sampled.

The results of this study did not confirm our starting hypothesis that the composition of benthic macroinvertebrate communities would be significantly different between mesohabitats. Although certain taxa were more abundant in a specific mesohabitat and the density of reophilous taxa associated with coarse mineral substrates (i.e., Ecological Group A sensu Usseglio-Polatera et al., 2000) in the riffle was higher than in pool and step-pool before the sediment flushing, the PERMANOVA and nMDS analyses showed consistent patterns in the composition of macroinvertebrate assemblages of different mesohabitats, both single and combined. In all cases, the community returned to the pre-flushing condition on 
the last sampling date, i.e., one year after the sediment flushing event, in correspondence of the same sampling month. Weak changes in taxonomic composition between mesohabitats might be explained by the prevailing effects of the natural and anthropogenic pressures on the regional pool of macroinvertebrate taxa, overriding those attributable to the physical characteristics of mesohabitats.

Besides a richness reduction, both total and EPT, on the first post-flushing sampling occasion in all mesohabitat scenarios, both metrics were not significantly affected by this kind of disturbance. A short-term nestedness effect of sediment flushing was already highlighted in our previous study (Doretto et al., 2021) and, also, we found that the impact of controlled sediment flushing operations on richness depends on the sediment dose characterizing the operation itself (Espa et al., 2019). Although an increased taxonomic resolution (i.e., genus and species level) could have improved our ability of detecting differences of taxon richness, it seems not the only reason explaining the patterns observed in this study: in fact, the mixed (i.e., genus and family) taxonomic resolution proved to be successful in previous research on fine sediment deposition due to natural and anthropogenic sources (Couceiro et al., 2010; Buendia et al., 2013). Other reasons explaining the limited effect observed on richness could be that regulated Alpine rivers, such as the Roasco Stream, are characterized by communities composed of few dominant taxa, including Baetis and Chironomidae, that are ubiquitous and opportunistic taxa characterized by traits enabling them to face disturbed conditions, and that the macroinvertebrate community of these regulated rivers is better structured in terms of richness and diversity during the cold season (i.e., Post03 in this study) (Quadroni et al., 2017). Moreover, it is possible that sediment flushing did not have relevant effect on the benthos richness since there was a continuous recolonization through drift from the unimpacted tributary (i.e., the Roasco di Sacco Stream). Indeed, recovery depends on multiple factors including not only temporal but also spatial scales, as well as the degree of integrity of the biological community (Doretto et al., 2018b). Another factor deserving proper attention and explaining the overall low richness characterizing the study stream is the relatively high slope of the investigated stream reach (see Study area and context), giving rise, in the sampling areas, to high sheer stress, i.e., a hydraulic parameter capable to shaping the macroinvertebrate community as well as the substrate (Gibbins et al., 2010).

However, it is worth highlighting that, differently from pool and step-pool, in the riffle, during the whole study period, richness did not regain the pre-flushing value, being the highest value recorded among the three mesohabitats (i.e., 19 as total taxon richness and 11 as EPT richness). In the other two mesohabitats, the recovery occurred after six months since the sediment flushing event.

Both total density and the density of taxa belonging to Ecological Group A were significantly impacted by sediment flushing and these results corroborate previous research demonstrating that fine sediment inputs impacted the density of stream macroinvertebrates rather than richness (Ciesielka and Bailey, 2001; de Castro Vasconcelos and Melo, 2008). A strong reduction (i.e., total density: 82-96\%, Ecological Group A density: 66-91\%) was observed in the first post-flushing sample in all mesohabitats. Though different values were recorded for each mesohabitat (mostly higher in the riffle), the temporal trajectory of total density was similar for all mesohabitats: the recovery started after three months from the sediment flushing event and was complete after six months, also favored by the season. The second density drop measured after nine months was probably associated to the flow increase typically occurring in late spring in the study area (Quadroni et al., 2017).

The density of the taxa belonging to Ecological Group A, as the stoneflies Perla and Nemouridae, the mayflies Epeorus and Rhitrogena, and the caddisflies Limnephilidae and Rhyacophilidae, recovered faster in the pool and riffle (i.e., after three months) than in the step-pool (i.e., after six months). Before the flushing, the highest value was recorded in the riffle, but if the whole study period is considered, it was reached in the pool, six months after the flushing event. This could be associated to the peak in abundance of Limnephilidae, probably favored by a higher availability of suitable materials for the construction of their cases (Statzner, 2011). Moreover, most upstream mesohabitats (i.e., pool and riffle) could be recolonized faster.

The temporal trajectories of the SILTES index reflected those of the three metrics included in its calculation. More specifically, it could detect the short-term impact of sediment flushing, the recovery within three or six months in the pool and step-pool and the absence of a complete recovery in the riffle. Conversely, the DFSI index was poorly sensitive to detecting these variations in the structure of benthic macroinvertebrate communities. This difference could be explained by an intrinsic characteristic of the two indices (Doretto et al., 2018a; Gieswein et al., 2019): the SILTES index includes a metric related to density (i.e., the density of macroinvertebrates belonging to Ecological Group A sensu Usseglio-Polatera et al., 2000) that was the parameter most affected by sediment flushing, while the DFSI index accounts for seven abundance classes. Another possible explanation might be that the change in the substrate composition of the three mesohabitats due to sediment deposition after flushing was not severe enough to induce a relevant change in the values of the DFSI index. Accordingly, only a slight increase of its value was recorded in the first post-flushing sample in the pool and riffle.

The results of combinations among mesohabitats were comparable to those obtained for single mesohabitats. On each occasion, they were influenced mainly by the data of the mesohabitat for which the highest values of the metric investigated were recorded. Especially in the case of density metrics and SILTES index, the results in terms of temporal trajectory and recovery to pre-flushing condition were different, and this could influence the ecological impact assessment of sediment flushing operations. If the SILTES index is used for this purpose, two approaches can be proposed in order to maximize ecosystem protection: monitoring all mesohabitats or only the most sensitive one, that, in this casestudy, is the riffle.

Until now, only few other studies have compared the effects of sedimentation events on benthic macroinvertebrate communities collected in different mesohabitats, detecting more relevant impact in runs or glides than in riffle areas (Hansen and Hayes, 2012; Salmaso et al., 2021).

For concluding, results from this study suggest that disturbances caused by the investigated sediment flushing 
were not large nor long enough to permanently alter the benthic invertebrate communities in the three analyzed mesohabitats. Despite some differences were detected in their biological response and riffle revealed the most sensitive mesohabitat, effects on richness, density and composition of benthic communities between mesohabitats were essentially comparable. However, when looking at these results some sitespecificities should be underlined. First, the study has been conducted in an area where a recolonization from upstream unimpacted river reaches is possible. Moreover, the area was impacted long since by hydropower exploitation, thus sustaining a benthic community able to recover quickly from related alterations. Different patterns could emerge from similar studies in pristine rivers or rivers devoid of significant recolonization sources. Thus, this research calls for further effort in field studies as the variables influencing river ecosystem integrity, the impact on and recovery times of local macroinvertebrate communities, are quite complex and may be different across study areas.

We are confident that this research may support water resource managers, environmental protection authorities and policy makers by offering reliable data on the assessment of the ecological impact of sediment flushing operations.

Acknowledgments. The authors thank Dr. Livia Servanzi, Dr. Andrea Facchin, and Dr. Andrea Longhi for their field and lab work.

\section{References}

Aksamit CK, Carolli M, Vanzo D, Weber C, Schmid M. 2021. Macroinvertebrate recovery to varying hydropeaking frequency: a small hydropower plant experiment. Front Environ Sci 8: 602374 .

Barbour MT, Gerritsen J, Snyder BD, Stribling JB. 1999. Rapid bioassessment protocols for use in streams and wadeable rivers: periphyton, benthic macroinvertebrates and fish. EPA 841-B99-002. U.S. Environmental Protection Agency.

Barnes JB, Vaughan IP, Ormerod SJ. 2013. Reappraising the effects of habitat structure on river macroinvertebrates. Freshw Biol 58: 2154-2167.

Beisel JN, Usseglio-Polatera P, Thomas S, Moreteau JC. 1998. Stream community structure in relation to spatial variation: the influence of mesohabitat characteristics. Hydrobiologia 389: 73-88.

Bisson PA, Montgomery DR, Buffington JM. 2017. Valley segments, stream reaches, and channel units. In: Lamberti GA, Hauer FR ed. Methods in Stream Ecology, Academic Press, Volume 1, pp. 21-47.

Buendia C, Gibbins CN, Vericat D, Lopez-Tarazon JA, Batalla RJ. 2011. Influence of naturally high fine sediment loads on aquatic insect larvae in a montane river. Scot Geogr J 127: 315-334.

Buendia C, Gibbins CN, Vericat D, Batalla RJ, Douglas A. 2013. Detecting the structural and functional impacts of fine sediment on stream invertebrates. Ecol Indic 25: 184-196.

Buffagni A, Erba S. 2007. Intercalibrazione e classificazione di qualità ecologica dei fiumi per la 2000/60/EC (WFD): l'indice STAR-ICMi. IRSA-CNR Notiziario dei metodi analitici 1: 94-100.

Buss DF, Carlisle DM, Chon TS, et al. 2015. Stream biomonitoring using macroinvertebrates around the globe: a comparison of largescale programs. Environ Monit Assess 187: 1-21.
Ciesielka IK, Bailey RC. 2001. Scale-specific effects of sediment burial on benthic macroinvertebrate communities. J Freshw Ecol 16: $73-81$.

Couceiro SRM, Hamada N, Forsberg BR, Padovesi-Fonseca C. 2010. Effects of anthropogenic silt on aquatic macroinvertebrates and abiotic variables in streams in the Brazilian Amazon. $J$ Soil Sediment 10: 89-103.

Crosa G, Castelli E, Gentili G, Espa P. 2010. Effects of suspended sediments from reservoir flushing on fish and macroinvertebrates in an alpine stream. Aquat Sci 72: 85-95.

de Castro Vasconcelos M, Melo AS. 2008. An experimental test of the effects of inorganic sediment addition on benthic macroinvertebrates of a subtropical stream. Hydrobiologia 610: 321-329.

De Pauw N, Gabriels W, Goethals PL. 2006. River monitoring and assessment methods based on macroinvertebrates. Chichester, UK: John Wiley and Son, Ltd., pp. 113-134.

Doretto A, Piano E, Bona F, Fenoglio S. 2018a. How to assess the impact of fine sediments on the macroinvertebrate communities of alpine streams? A selection of the best metrics. Ecol Indic 84: $60-69$.

Doretto A, Piano E, Falasco E, Fenoglio S, Bruno MC, Bona F. 2018b. Investigating the role of refuges and drift on the resilience of macroinvertebrate communities to drying conditions: an experiment in artificial streams. River Res Appl 34: 777-785.

Doretto A, Bo T, Bona F, Apostolo M, Bonetto D, Fenoglio S. 2019. Effectiveness of artificial floods for benthic community recovery after sediment flushing from a dam. Environ Monit Assess 191: 88.

Doretto A, Bo T, Bona F, Fenoglio S. 2020. Efficiency of Surber net under different substrate and flow conditions: insights for macroinvertebrates sampling and river biomonitoring. Knowl Manag Aquat Ecol 421: 10.

Doretto A, Piano E, Fenoglio S, et al. 2021. Beta-diversity and stressor specific index reveal patterns of macroinvertebrate community response to sediment flushing. Ecol Indic 122: 107256.

Espa P, Castelli E, Crosa G, Gentili G. 2013. Environmental effects of storage preservation practices: controlled flushing of fine sediment from a small hydropower reservoir. Environ Manage 52: 261-276.

Espa P, Crosa G, Gentili G, Quadroni S, Petts G. 2015. Downstream ecological impacts of controlled sediment flushing in an Alpine valley river: a case study. River Res Appl 31: 931-942.

Espa P, Brignoli ML, Crosa G, Gentili G, Quadroni S. 2016. Controlled sediment flushing at the Cancano Reservoir (Italian Alps): management of the operation and downstream environmental impact. J Environ Manag 182: 1-12.

Espa P, Batalla RJ, Brignoli ML, Crosa G, Gentili G, Quadroni S. 2019. Tackling reservoir siltation by controlled sediment flushing: impact on downstream fauna and related management issues. Plos One 14: $\mathrm{e} 0218822$.

Folegot S, Bruno MC, Larsen S, et al. 2021. The effects of a sediment flushing on Alpine macroinvertebrate communities. Hydrobiologia $1-21$.

Friberg N, Baattrup-Pedersen A, Pedersen ML, Skriver J. 2005. The new Danish stream monitoring programme (NOVANA) preparing monitoring activities for the water framework directive era. Environ Monit Assess 111: 27-42.

Gibbins C, Vericat D, Batalla RJ. 2007. When is stream invertebrate drift catastrophic? The role of hydraulics and sediment transport in initiating drift during flood events. Freshw Biol 52: 2369-2384.

Gibbins C, Batalla RJ, Vericat D. 2010. Invertebrate drift and benthic exhaustion during disturbance: response of mayflies (Ephemeroptera) to increasing shear stress and riverbed instability. River Res Appl 26: 499-511. 
Gieswein A, Hering D, Lorenz AW. 2019. Development and validation of a macroinvertebrate-based biomonitoring tool to assess fine sediment impact in small mountain streams. Sci Total Environ 652: 1290-301.

Gordon ND, McMahon TA, Finlayson BL, Gippel CJ, Nathan RJ. 2004. Stream hydrology: an introduction for ecologists. John Wiley and Sons.

Halwas KL, Church M, Richardson JS. 2005. Benthic assemblage variation among channel units in high-gradient streams on Vancouver Island, British Columbia. J N Am Benthol Soc 24: 478-494.

Hansen JF, Hayes DB. 2012. Long-term implications of dam removal for macroinvertebrate communities in Michigan and Wisconsin rivers, United States: macroinvertebrate response to dam removal. River Res Appl 28: 1540-1550.

Herbst DB, Cooper SD, Medhurst RB, Wiseman SW, Hunsaker CT. 2018. A comparison of the taxonomic and trait structure of macroinvertebrate communities between the riffles and pools of montane headwater streams. Hydrobiologia 820: 115-133.

Hitchman SM, Mather ME, Smith JM, Fencl JS. 2018. Identifying keystone habitats with a mosaic approach can improve biodiversity conservation in disturbed ecosystems. Glob Change Biol 24: 308321.

Kondolf GM, Gao Y, Annandale GW, et al. 2014. Sustainable sediment management in reservoirs and regulated rivers: experiences from five continents. Earth'; Future 2: 256-280.

Mathers KL, Wood PJ. 2016. Fine sediment deposition and interstitial flow effects on macroinvertebrate community composition within riffle heads and tails. Hydrobiologia 776: 147-160.

Oksanen J, Blanchet FG, Friendly M, et al. 2015. Vegan: Community Ecology Package. R Package Version 2. 2-1.
Owens PN, Batalla RJ, Collins AJ, et al. 2005. Fine-grained sediment in river systems: environmental significance and management issues. River Res Appl 21: 693-717.

Quadroni S, Brignoli ML, Crosa G, et al. 2016. Effects of sediment flushing from a small Alpine reservoir on downstream aquatic fauna. Ecohydrology 9: 1276-1288.

Quadroni S, Crosa G, Gentili G, Espa P. 2017. Response of stream benthic macroinvertebrates to current water management in Alpine catchments massively developed for hydropower. Sci Total Environ 609: 484-496.

R Core Team. 2019. R: A Language and Environment for Statistical Computing. R Foundation for Statistical Computing, Vienna, Austria. https://www.R-project.org/.

Rosenberg DM, Resh VH. 1993. Freshwater biomonitoring and benthic macroinvertebrates (No. 504. 4 FRE). New York, NY, USA: Chapman \& Hall

Salmaso F, Espa P, Crosa G, Quadroni S. 2021. Impacts of fine sediment input on river macroinvertebrates: the role of the abiotic characteristics at mesohabitat scale. Hydrobiologia 1-21.

Silva DR, Ligeiro R, Hughes RM, Callisto M. 2014. Visually determined stream mesohabitats influence benthic macroinvertebrate assessments in headwater streams. Environ Monit Assess 186: $5479-5488$.

Statzner B. 2011. Mineral grains in caddisfly pupal cases and streambed sediments: assessing resource use and its limitation across various river types. Ann Limnol-Int J Lim 47: 103-118.

Usseglio-Polatera P, Bournaud M, Richoux P, Tachet H. 2000. Biological and ecological traits of benthic freshwater macroinvertebrates: relationships and definition of groups with similar traits. Freshw Biol 43: 175-205.

Cite this article as: Doretto A, Espa P, Salmaso F, Crosa G, Quadroni S. 2022. Considering mesohabitat scale in ecological impact assessment of sediment flushing. Knowl. Manag. Aquat. Ecosyst., 423, 2. 